Research Article

\title{
Research and Performance Test of New Full-Length Anchorage Material
}

\author{
Shunjie Huang $\mathbb{D},{ }^{1,2}$ Xiangrui Meng, ${ }^{1,2}$ Guangming Zhao $\mathbb{D}^{1,2}$ Yingming Li ${ }^{10},{ }^{1,2}$ \\ Xiang Cheng $\mathbb{D},{ }^{1,2,3}$ Wensong $X u \mathbb{D}^{1,2}$ and Gang Liu $\mathbb{D}^{1,2,4}$ \\ ${ }^{1}$ State Key Laboratory of Mining Response and Disaster Prevention and Control in Deep Coal Mines, \\ Anhui University of Science and Technology, Huainan 232001, China \\ ${ }^{2}$ Key Laboratory of Ministry of Education for Efficient Coal Working Sponsored Jointly by \\ Anhui Province and Ministry of Education, Anhui University of Science and Technology, Huainan, Anhui 232001, China \\ ${ }^{3}$ Post-Doctoral Research Station, Huaibei Mining Corporation Limited, Huaibei 235006, China \\ ${ }^{4}$ Heilongjiang Ground Pressure \& Gas Control in Deep Mining Key Lab, Heilongjiang University of Science \& Technology, \\ Harbin 150022, China
}

Correspondence should be addressed to Guangming Zhao; guangmingzhao@163.com

Received 1 April 2021; Accepted 26 May 2021; Published 4 June 2021

Academic Editor: Xianjie Hao

Copyright $\odot 2021$ Shunjie Huang et al. This is an open access article distributed under the Creative Commons Attribution License, which permits unrestricted use, distribution, and reproduction in any medium, provided the original work is properly cited.

It is difficult to support roadway with anchor cable in view of impact tendency in impinging liability roadway; a new material of inorganic and high-performance full-length anchoring material for anchoring cable is developed by adding several modifiers with ultrafine cement as the main material. The purpose is to improve the mechanical properties and durability of cement-based materials, improve the coordination of anchor cable support system, and ensure the stability of surrounding rock of mining roadway. The new full-length anchoring material is developed by optimizing the proportion of different components of the material, and the mechanical properties of the new material were studied. The anchoring force of resin anchoring agent, ordinary Portland cement, blank ultrafine cement, and new full-length anchoring material are tested. Based on SEM microscopic characterization, the fracture types and failure characteristics of resin anchoring agent and full-length anchoring material are researched. The results show that the optimal content of each component of the new inorganic high-performance full-length anchorage material is as follows: the content of component $\mathrm{A}$ is $15 \%$, the content of component $\mathrm{B}$ is $3 \%$, the content of component $\mathrm{C}$ is $0.2 \%$, the content of component $\mathrm{D}$ is $1 \%$, and the content of component $\mathrm{E}$ is $1 \%$; the tensile test shows that the full-length anchoring material has good bonding property, high anchoring strength, strong stability, and good rock coupling. SEM microstructure and morphology analysis have showed that the new anchorage materials can fully hydrate each other, resulting in a relatively dense stone body. The new full-length anchoring material can effectively improve the anchoring force and improve the stability of the anchor cable and has significant performance advantages and good engineering applicability, and it has the advantages of lower cost and safer to use. The new material is a very good supporting material for roadway.

\section{Introduction}

In the process of coal mining in the western region of China (Loess Plateau region), the roof of coal seam is mostly mudstone with poor cementing property. Its main characteristics are as follows: low strength, obvious bedding, being easy to hydrophilic, and water expansion. In the process of proceeding of excavation, the coal and rock mass of the roadway roof have impact tendency, and the frequent occurrence of "coal cannon" damages the integrity and continuity of surrounding rock and leads to the development of surrounding rock fractures and the decrease of surrounding rock strength [1-3]. The occurrence of this situation puts forward higher requirements for roadway support system [4]. If the conventional anchor cable support system is used for support, the failure of anchor cable and roof subsidence will often be caused by the broken coal and rock mass above the roof due to repeated impact. Ceiling 
accidents can occur in severe cases; the research on support system under rock burst environment has become an increasingly important research topic $[5,6]$. At present, the auxiliary means to deal with rock burst support system mainly include the following: lengthen the anchor cable and increase the density of anchor cable, rock grouting, and so forth. The lengthening of the anchor cable increases the length of the anchor cable in the hole, which increases the expansion of the anchor cable and weakens the supporting force. When end anchorage is carried out, there is no viscous anchor force between the free section of anchor bolt and the surrounding rock, and there is a certain gap between the free section of anchor bolt and the surrounding rock, and the surrounding rock is prone to dislocation and instability. However, the long free section of end anchorage leads to large axial displacement, and the joint position is not affected by viscous anchor force, so the support body is prone to shear failure [7]. With the increase of anchor cable density, the surrounding rock will be more broken and the difficulty of support will increase. Due to the large discontinuous deformation of roadway surrounding rock, the phenomenon of anchor cable breaking gradually increases, and the support strength greatly decreases, which can easily lead to roadway roof collapse and sidewall slapping, seriously affecting the safety of underground operation [8]. Many scholars have started from roadway roof grouting to reinforce surrounding rock and reconsolidate roof through grouting filling surrounding rock cracks [9-11]. However, the field investigation has found that not only has the layout of grouting pipe increased the workload, but also it is difficult to achieve the desired effect. Through theoretical and experimental studies, Chen et al. [12] have concluded that full anchor has better anchoring effect than end anchor. The conclusion was that the anchoring agent can resist the deformation of rock mass together with the bolt and can effectively prevent the stratification and dislocation of surrounding rock mass. In order to increase the prestress of anchor cable, the quantity of resin anchoring agent is increased to increase the anchoring length. However, the resin anchoring agent is characterized by its viscosity, large particle size, fast solidification time, and difficulty in dilution. Moreover, it is difficult to penetrate into the cracks between coal and rock masses and has poor cementation ability to the fractured area of drilling. The increase of anchoring length requires extremely high requirements for anchor drill [13]. According to the field investigation, long anchor cables are generally used for roadway support under the environment of rock burst (e.g., $7.4 \mathrm{~m}, 8.6 \mathrm{~m}$, and $9.8 \mathrm{~m}$ ), and this is basically unable to achieve full length anchorage of resin anchoring agent for anchor cables. Therefore, new inorganic materials must be developed to realize full-length anchorage. In view of the failure of anchor cable in some areas caused by the serious deformation of rock burst roadway surrounding rock, the idea of "end anchoringfilling in the broken zone-restoring in situ" is adopted. That is, the anchor cable is installed at the end of the anchor, and the new inorganic material is used to fill the "suspended part" after the prestressing is applied to achieve full-length anchorage. Coupling the anchor cable and surrounding rock can improve the coordination and stability of the supporting system. The material properties need to have "micro permeability, high strength, strong bonding, injectability"; "micro penetration" is to reduce the particle size of the material molecule and increase the fluidity and it can better diffuse into the micro cracks, so as to improve the anchoring force; "high strength" means that the material is modified to meet the strength requirements by optimizing the material ratio and adding special reinforcing agent. "Bonding" is the addition of tiny amounts of nanoorganic modifiers; it increases the hydration reaction of the material to form a high strength chemical bond to improve the bonding force between the anchoring material and the surrounding rock and the anchor cable. "Injectability" means anchoring by means of anchoring with special devices to reduce workers' workload and improve tunneling efficiency. In addition, the new type of anchoring material can penetrate into the cracks and increase the contact area between the anchoring system and surrounding rock, so that the supporting body and surrounding rock have a better coupling.

At present, there are few studies on full-length anchorage; relevant domestic and foreign regulations also do not specify a unified industry standard, especially for the uneven development of cracks in roadway surrounding rock and the difficulty of anchor cable support. The use of conventional Portland cement particles is larger, and the injectability is limited to large cracks. If the water-cement ratio increases, the stone rate and strength will decrease. If the water-cement ratio is reduced, the injectability will be greatly reduced, which cannot meet the needs of engineering. In order to solve this problem, a new type of inorganic anchoring material is developed by adding some modifiers and using ultrafine cement as the main material through proportioning experiment. The anchoring performance of the new material is tested by designing the bolt pull-out experiment. The development of new materials further guarantees the stability of the anchor cable support system for loose and broken surrounding rock. This research has remarkable economic benefit, practical value, and popularization and application prospect.

\section{Preparation of Full-Length Anchoring Materials}

2.1. Material Optimization. In this paper, HPC superfine cement with high resistance is used as the matrix material. Composite reinforced stabilizer, expansion agent, and super high-performance water reducer are selected as auxiliary modified materials; they enhance the strength of full-length anchoring material and anchoring adhesion and other properties.

Cement-based materials are as follows: with high-resistance HPC superfine cement as the main body, the strength grade is $42.5 \mathrm{MPa}$, the content of tricalcium silicate $\left(\mathrm{C}_{3} \mathrm{~S}\right)$ is $44.72 \%$, tricalcium aluminate $\left(\mathrm{C}_{3} \mathrm{~S}\right)$ is $2.35 \%, \mathrm{MgO}$ is $3.10 \%$, and the specific surface area is $630 \mathrm{~m}^{2} / \mathrm{kg}$. The median particle size is $D_{50}$ and $10.20 \mu \mathrm{m}$, and its particle size distribution is shown in Figure 1. Component $\mathrm{A}$ is a kind of material with good workability and good injectability and 


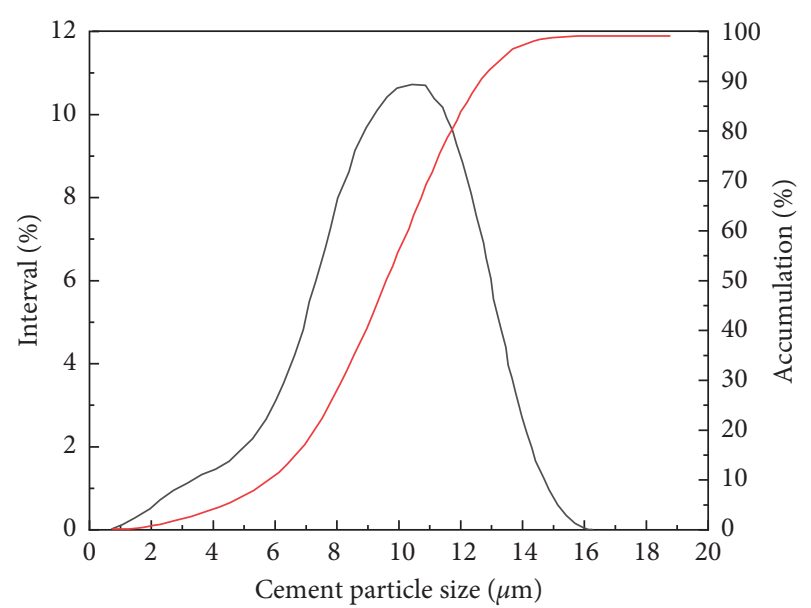

FIgUre 1: Cement particle size distribution.

can improve the impact resistance of material; its burning loss is $2.48 \%, \mathrm{Fe}_{2} \mathrm{O}_{3}$ content is $3.87 \%$, $\mathrm{CaO}$ content is $2.27 \%$, $\mathrm{MgO}$ content is $0.81 \%, \mathrm{Al}_{2} \mathrm{O}_{3}$ content is $29.09 \%$, and $\mathrm{SiO}_{2}$ content is $53.36 \%$. Component $\mathrm{B}$ is an organic admixture with reducing water, improving cement-based strength, and preventing shrinkage. The content of chloride ion is $0.01 \%$, $\mathrm{pH}$ value is 5.5 , and there is no corrosion effect on reinforcement. Component $\mathrm{C}$ has the characteristics of good cement adaptability, micro expansion, and strong durability. Component $\mathrm{D}$ has stable microexpansion, and its main component is $29 \% \mathrm{MgO}$. The alkali content is $4.12 \%$, and $180 \mathrm{~d}$ longitudinal limit shrinkage rate $<0.02 \%$. With early strength, it increases the compressive resistance, flexural resistance, and reinforcement bonding force and reduces bleeding rate. Component $\mathrm{E}$ starts to adjust the $\mathrm{pH}$ value, improve the bonding force, and increase the compactness.

The hydration reaction of ultrafine cement with high resistance to HPC is a physical and chemical process that includes the dissolution of minerals, the precipitation of ions, the crystallization of new minerals, the precipitation of products, the bonding, and the nucleation. The approximate expression of hydration reaction of ultrafine cement minerals with high resistance to HPC is [14-16]

$$
\begin{gathered}
\mathrm{C}_{3} \mathrm{~S}+n \mathrm{H} \longrightarrow \mathrm{C}-\mathrm{S}-\mathrm{H}+(3-x) \mathrm{CH} \\
\mathrm{C}_{2} \mathrm{~S}+m \mathrm{H} \longrightarrow \mathrm{C}-\mathrm{S}-\mathrm{H}+(2-x) \mathrm{CH} \\
\mathrm{C}_{3} \mathrm{~A}+6 \mathrm{H} \longrightarrow \mathrm{C}_{3} \mathrm{AH}_{6} \\
\mathrm{C}_{3} \mathrm{~A}+\mathrm{CH}+12 \mathrm{H} \longrightarrow \mathrm{C}_{4} \mathrm{AH}_{13} \\
\mathrm{C}_{4} \mathrm{AH}_{13}+3 \mathrm{CSH}_{2}+14 \mathrm{H} \longrightarrow \mathrm{C}_{3} \mathrm{~A} \cdot 3 \mathrm{CS} \cdot \mathrm{H}_{32}+\mathrm{CH} \\
\mathrm{C}_{4} \mathrm{AF}+2 \mathrm{CH}+10 \mathrm{H} \longrightarrow 2 \mathrm{C}_{3}(\mathrm{~A}, \mathrm{~F}) \mathrm{H}_{6}
\end{gathered}
$$

Equation (1) indicates that $\mathrm{C}_{3} \mathrm{~S}$ react and produce $\mathrm{C}-$ $\mathrm{S}-\mathrm{H}$ and $\mathrm{CH}$; the hydration reaction is fast and the early strength of stone body is high, The hydration products and structure of $\mathrm{C}_{3} \mathrm{~S}$ determine the performance of ultrafine cement paste. Equation (2) indicates that $\mathrm{C}_{2} \mathrm{~S}$ hydration reaction has occurred, and the reaction speed is relatively slow. Equations (3) (5) indicate hydration reaction of $\mathrm{C}_{3} \mathrm{~A}$, in this process, the reaction is rapid, the strength increases quickly, and the strength growth is not obvious in the later stage. Equation (6) indicates hydration reaction of $\mathrm{C}_{4} \mathrm{AF}$, the reaction rate is between $\mathrm{C}_{3} \mathrm{~S}$ and $\mathrm{C}_{3} \mathrm{~A}$, and the speed of strength improvement is between the two aspects, which can promote the later strength improvement.

2.2. Test Methods. Orthogonal experimental design is a kind of experimental design method to study multiple factors and multiple levels. According to the orthogonality, some representative points are selected from the comprehensive test for the test. These representative points have the characteristics of uniform dispersion and neat comparison. Orthogonal experimental design is the main method of fractional factorial design. Compared with the multifactor test, the orthogonal test has shorter period and lower cost and can get the ideal formula faster. The orthogonal experiment is based on the two principles of "equilibrium dispersion" and "neat comparability," and representative test sites are selected for the test and evenly dispersed to make the selected test sites representative and comparable. It is convenient for the processing and analysis of test data in the later stage, which can greatly reduce the workload of test and analysis $[17,18]$.This experiment is designed as 5 factors and 5 levels, with ultrafine cement as the matrix and 5 different components as the variables. They are represented by A, B, $\mathrm{C}, \mathrm{D}$, and $\mathrm{E}$, respectively. The orthogonal test table is the factor and level of $L_{25}\left(5^{5}\right)$, as shown in Table 1 .

2.3. Test Process. According to the orthogonal experimental design, each component was weighed accurately by electronic scale, the weighing materials were mixed, and the calculated amount of water was added. Then, the agitator was used to stir evenly, and the stirring time was $85 \sim 90 \mathrm{~s}$ to ensure that all components could be mixed evenly. The mixed cement slurry was loaded into a standard cube triplet test die of $70.7 \mathrm{~mm} \times 70.7 \mathrm{~mm} \times 70.7 \mathrm{~mm}$ (the test mold should be oiled first, which was conducive to the later demoulding) and vibrated on the plastic sand vibrator to eliminate the bubbles and increase the compactness. Finally, it needed to smooth the surface. The electronic scale and vibrating platform are shown in Figure 2.

For sample curing, the finished sample needs to be cured for 12 hours before demoulding. After demoulding, put it into the curing box for maintenance under constant temperature and humidity environment.

2.4. Analysis of Test Results. According to JGJ/T 70-2009 《Standard for Test Methods of Basic Properties of Building Mortar 》, test the compressive strength of stones at different curing ages; this was using the WAW-2000 hydraulic servo universal testing machine. Combined with the acoustic emission test system, the uniaxial compressive strength of 
TABLE 1: Orthogonal test factors and levels.

\begin{tabular}{lccccc}
\hline \multirow{2}{*}{ Level } & \multicolumn{3}{c}{ Factor (different components and contents) } \\
& $\mathrm{A}(\%)$ & $\mathrm{B}(\%)$ & $\mathrm{C}(\%)$ & $\mathrm{D}(\%)$ & 1 \\
1 & 1 & 1 & 0.1 & 2 & 1 \\
2 & 5 & 2 & 0.2 & 4 & 2 \\
3 & 10 & 3 & 0.3 & 6 & 3 \\
4 & 15 & 4 & 0.4 & 4 \\
5 & 20 & 5 & 0.5 & 5 \\
\hline
\end{tabular}

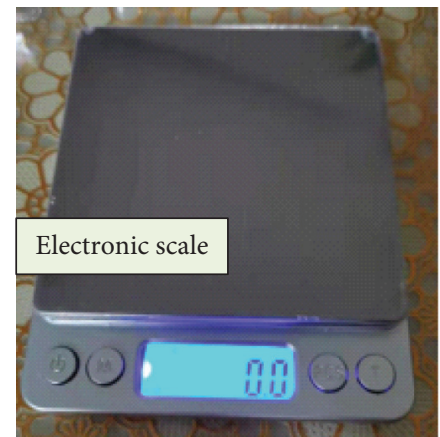

(a)

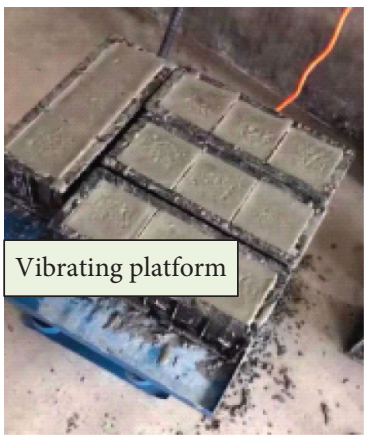

(b)

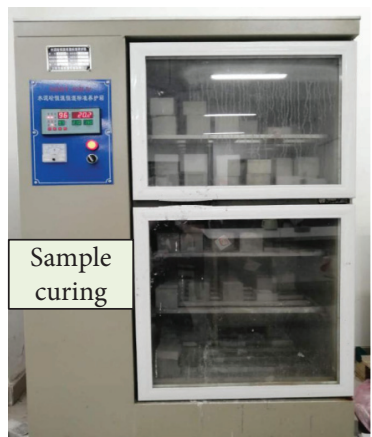

(c)

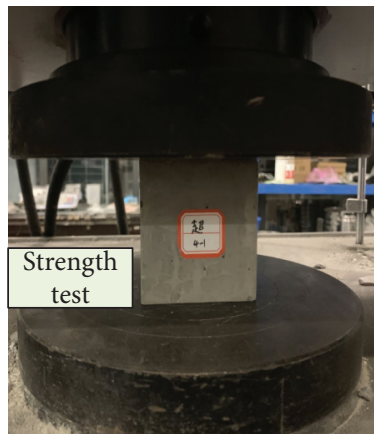

(d)

Figure 2: Test instrument and process.

curing age of $1 \mathrm{~d}, 3 \mathrm{~d}$, and $7 \mathrm{~d}$ was measured. The test results are shown in Table 2.

According to the above orthogonal test results, the relationship curve of the strength and compressive strength of the stone body under each factor could be drawn, as shown in Figure 3.

As can be seen from Figure 3(a), with the content of component $\mathrm{A}$ at $5 \%$, it had an influence on the late strength. When the content was $5 \% \sim 10 \%$, the strength of the later stage was greatly improved. When the content was $15 \%$, the $3 \mathrm{~d}$ strength increased by $29.4 \%$, and the $7 \mathrm{~d}$ strength increased by $43.6 \%$. When component A was more than $15 \%$, the early and late strength were decreased. As shown in Figure 3(b), although the intensity of component B was low at the early stage when the content of component B was $3 \%$, its intensity increased significantly on $3 \mathrm{~d}$ and $7 \mathrm{~d} .3 \mathrm{~d}$ strength was increased by $46.03 \%$ and $7 \mathrm{~d}$ strength was increased by $65.82 \%$. As could be seen from Figure 3(c), when the content of component $\mathrm{C}$ was $0.2 \%$ and $0.4 \%$, the intensity on $3 \mathrm{~d}$ and $7 \mathrm{~d}$ was significantly improved. When the content was $0.2 \%$, the $3 \mathrm{~d}$ strength was increased by $41.09 \%$, and the $7 \mathrm{~d}$ strength was increased by $43.65 \%$, and component $\mathrm{C}$ regulates the fluidity of the slurry, but it had shrinkage, so the amount could not be too much. As can be seen from Figure $3(\mathrm{~d})$, the strength can be significantly increased when the component B content was $4 \%$, which was $34.78 \%$ higher on $3 \mathrm{~d}$ and $40.20 \%$ higher on $7 \mathrm{~d}$. It could be seen from Figure $3(\mathrm{e})$ that the addition of $\mathrm{E}$ reduces the strength of the stone body. The strength of calculi was higher when the content was $1 \%$, which was increased by $31.36 \%$ at $3 \mathrm{~d}$ and $61.11 \%$ at $7 \mathrm{~d}$. By comparing the strength properties of different components, the optimal matrix composition of the material was $15 \%$ of component $\mathrm{A}, 3 \%$ of component $\mathrm{B}$, $0.2 \%$ of component C, $1 \%$ of component $\mathrm{D}$, and $1 \%$ of component E. Therefore, group A24 was the optimal combination.

\section{Material Anchorage Performance Test}

It is a very important index to evaluate the performance of materials to study the anchoring force and failure mode of materials [19-21]. Traditional anchoring materials were usually brittle and had low anchoring force, and they bond poorly with the bolt/cable. This was primarily because traditional materials had larger particle size and lower overall strength. At present, the resin anchoring agent used in mine had large consistency and high requirement to anchor drill. In order to compare the anchoring force difference between the new full-length anchoring material and the traditional cement material and resin anchoring agent, the anchor rod pulling test was conducted. In order to verify the influence of various factors on the adhesion of the new inorganic anchoring material, the mineral resin anchoring agent, ordinary Portland cement, and new inorganic anchoring material were compared and tested. The anchorage strength was used as the test index, the pullout test was carried out, and the acoustic emission was used as the auxiliary, so as to better understand the failure characteristics in the process of anchorage failure. AE energy was to highlight the AE time characteristics at a certain moment; $\mathrm{AE}$ counts and cumulative energy can evaluate the characteristics of the whole process of acoustic emission [13]. 
TABLE 2: Orthogonal test results.

\begin{tabular}{|c|c|c|c|c|c|c|c|c|}
\hline \multirow{2}{*}{ Test number } & \multicolumn{5}{|c|}{ Material mass fraction (\%) } & \multicolumn{3}{|c|}{ Compressive strength (MPa) } \\
\hline & $\mathrm{A}$ & $\mathrm{B}$ & $\mathrm{C}$ & $\mathrm{D}$ & $\mathrm{E}$ & $1 \mathrm{~d}$ & $3 \mathrm{~d}$ & $7 \mathrm{~d}$ \\
\hline A1 & 1 & 1 & 0.1 & 1 & 1 & 17.3 & 19.8 & 20.1 \\
\hline $\mathrm{A} 2$ & 5 & 2 & 0.2 & 2 & 2 & 18.26 & 20.89 & 20.01 \\
\hline $\mathrm{A} 3$ & 10 & 3 & 0.3 & 4 & 3 & 26.28 & 32.63 & 36.63 \\
\hline A4 & 15 & 4 & 0.4 & 6 & 4 & 29.56 & 34.01 & 42.84 \\
\hline A5 & 20 & 5 & 0.5 & 8 & 5 & 23.46 & 28.61 & 29.56 \\
\hline A6 & 1 & 2 & 0.3 & 6 & 5 & 20.14 & 24.04 & 30.65 \\
\hline A7 & 5 & 3 & 0.4 & 8 & 1 & 18.65 & 36.76 & 48.2 \\
\hline A8 & 10 & 4 & 0.5 & 1 & 2 & 23.59 & 33.49 & 33.51 \\
\hline A9 & 15 & 5 & 0.1 & 2 & 3 & 23.92 & 30.2 & 30.24 \\
\hline A10 & 20 & 1 & 0.2 & 4 & 4 & 31.95 & 43.66 & 42.23 \\
\hline A11 & 1 & 3 & 0.5 & 2 & 4 & 21.91 & 26.77 & 30.17 \\
\hline A12 & 5 & 4 & 0.1 & 4 & 5 & 19.96 & 25.16 & 23.95 \\
\hline A13 & 10 & 5 & 0.2 & 6 & 1 & 25.51 & 35.57 & 34.79 \\
\hline A14 & 15 & 1 & 0.3 & 8 & 2 & 34.72 & 36.89 & 39.24 \\
\hline A15 & 20 & 2 & 0.4 & 1 & 3 & 30.72 & 36.63 & 30.45 \\
\hline A16 & 1 & 4 & 0.2 & 8 & 3 & 20.18 & 27.35 & 31.36 \\
\hline A17 & 5 & 5 & 0.3 & 1 & 4 & 25.14 & 32.51 & 25.33 \\
\hline A18 & 10 & 1 & 0.4 & 2 & 5 & 32.17 & 37.92 & 31.35 \\
\hline A19 & 15 & 2 & 0.5 & 4 & 1 & 29.23 & 39.81 & 46.92 \\
\hline A20 & 20 & 3 & 0.1 & 6 & 2 & 24.11 & 30.18 & 32.54 \\
\hline A21 & 1 & 5 & 0.4 & 4 & 2 & 18.42 & 28.35 & 26.75 \\
\hline A22 & 5 & 1 & 0.5 & 6 & 3 & 21.45 & 31.75 & 18.66 \\
\hline A23 & 10 & 2 & 0.1 & 8 & 4 & 26.97 & 33.78 & 36.68 \\
\hline A24 & 15 & 3 & 0.2 & 1 & 5 & 27.5 & 46.64 & 48.88 \\
\hline A 25 & 20 & 4 & 0.3 & 2 & 1 & 27.92 & 20.95 & 33.39 \\
\hline
\end{tabular}

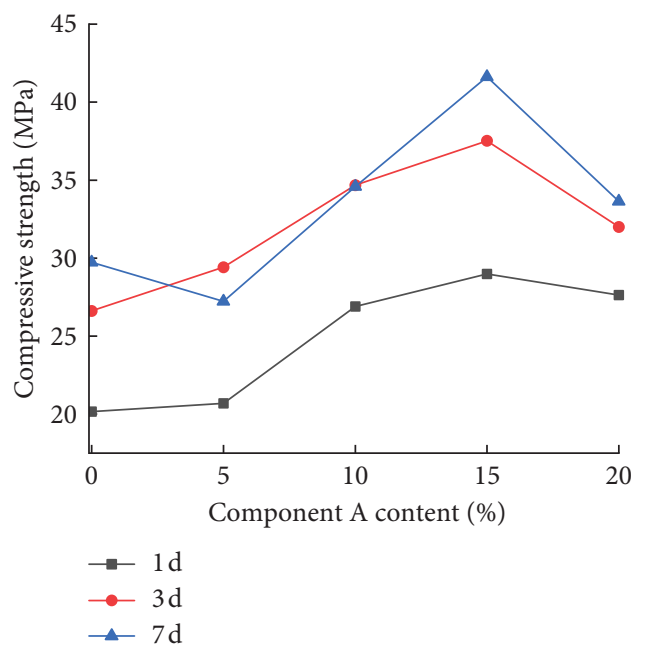

(a)

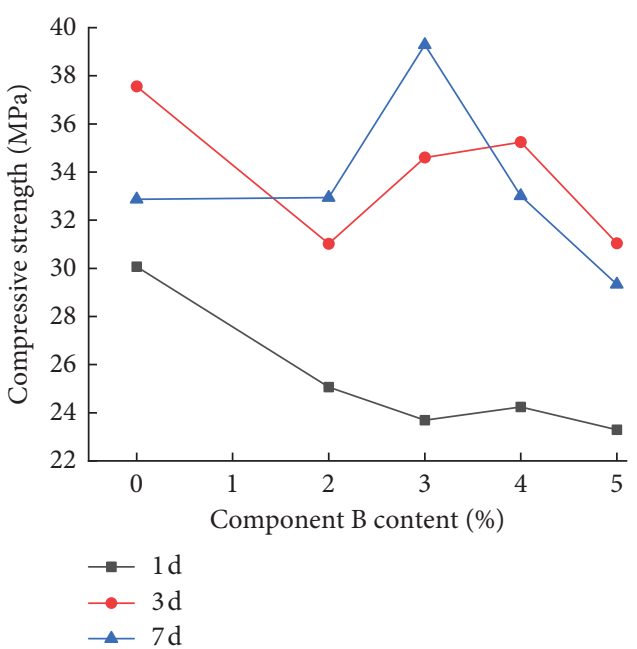

(b)

Figure 3: Continued. 


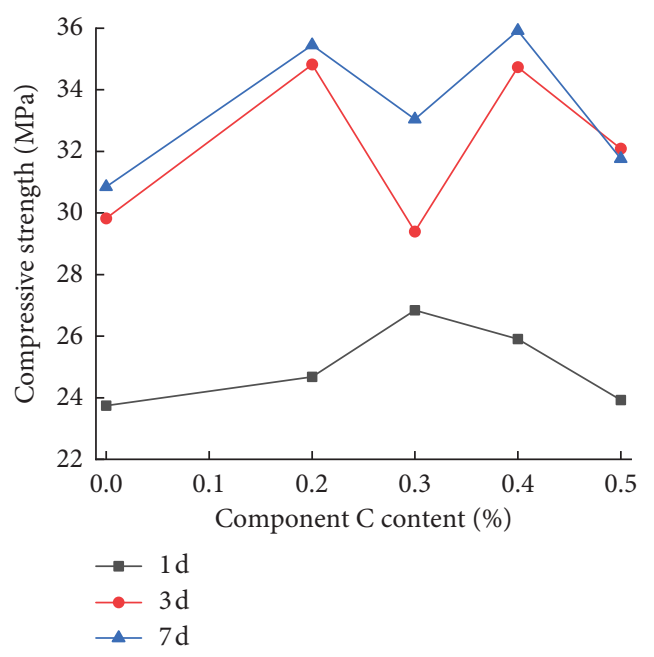

(c)

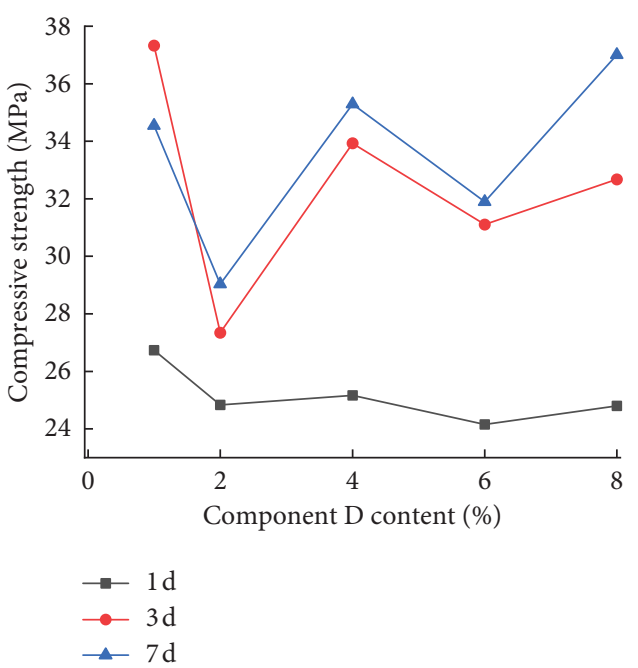

(d)

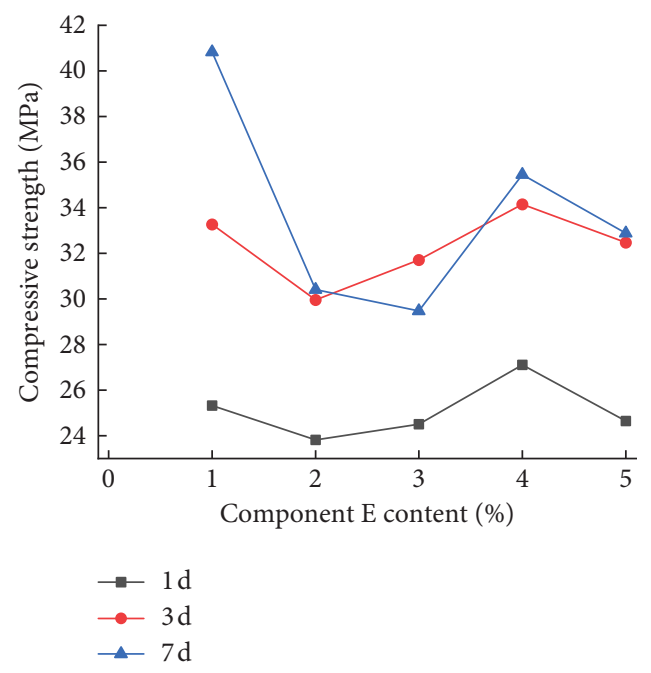

(e)

Figure 3: Relationship curves between different component contents and stone body strength.

3.1. Test Scheme. In order to test the shear resistance of the new anchoring material, the pull-out resistance of the bolt was simulated. In this test, the anchor rod diameter $\varphi=20 \mathrm{~mm}$, length $=140 \mathrm{~mm}$ dextral rebar, and the end had the grinding process. The anchorage matrix was made of granite with hard material and good uniformity. Its size was length $\times$ width $\times$ height $=100 \mathrm{~mm} \times 100 \mathrm{~mm} \times 100 \mathrm{~mm}$, the borehole was set at the center of the granite, and the diameter of the borehole was $\varphi 30 \mathrm{~mm}$. When the granite specimen was placed horizontally, it was necessary to make sure that the steel bar was in the center of the hole. The hole bottom was sealed with transparent tape to ensure that the steel bar was clearly in the center position. Then the modified slurry was added for casting. After curing the prepared specimen with anchor rod for $7 \mathrm{~d}$, the anchoring force test of bolt was carried out by using WAW-2000 universal testing machine and DS-2 acoustic emission system. The prepared sample is shown in Figure 4.
3.2. Test Process. In order to test the anchoring performance of the new type of anchoring material, at the same time, the anchoring force of resin anchoring agent and blank ultrafine cement material were compared. This test adopted WAW-2000 microcomputer control universal testing machine and Softisland DS-2 acoustic emission monitoring system, and the test system is shown in Figure 5. In this experiment, due to the large and hard granite matrix, compression test was used to replace the pull-out test, and the prepared and maintained anchorage specimen was fixed, and the acoustic emission probe sensor was fixed as well. When the preliminary work was ready, start the press, and it was at a loading rate of $0.05 \mathrm{MPa} / \mathrm{s}$, until the bolt was "pressed out." The failure test of anchorage material was finished. In this experiment, four different anchoring materials were used for testing. Through the comparative analysis of the test data, it was concluded that the anchoring agent was good. 


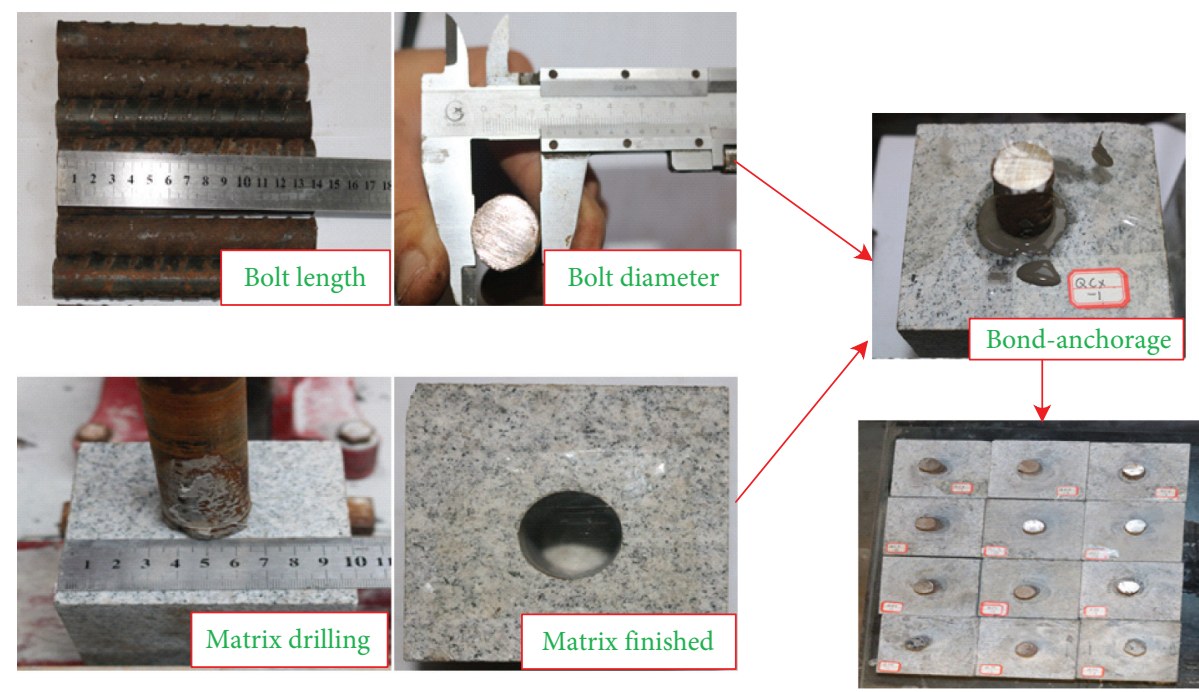

FIgURE 4: Preparation of anchorage specimen.

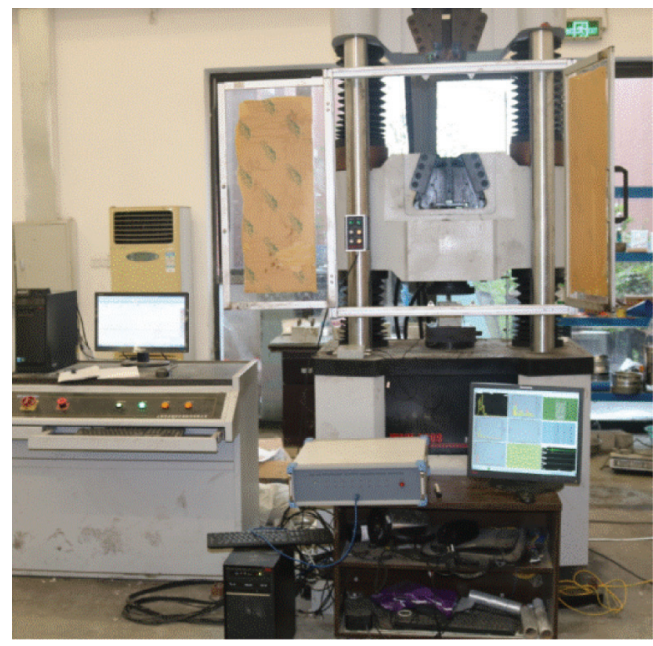

(a)

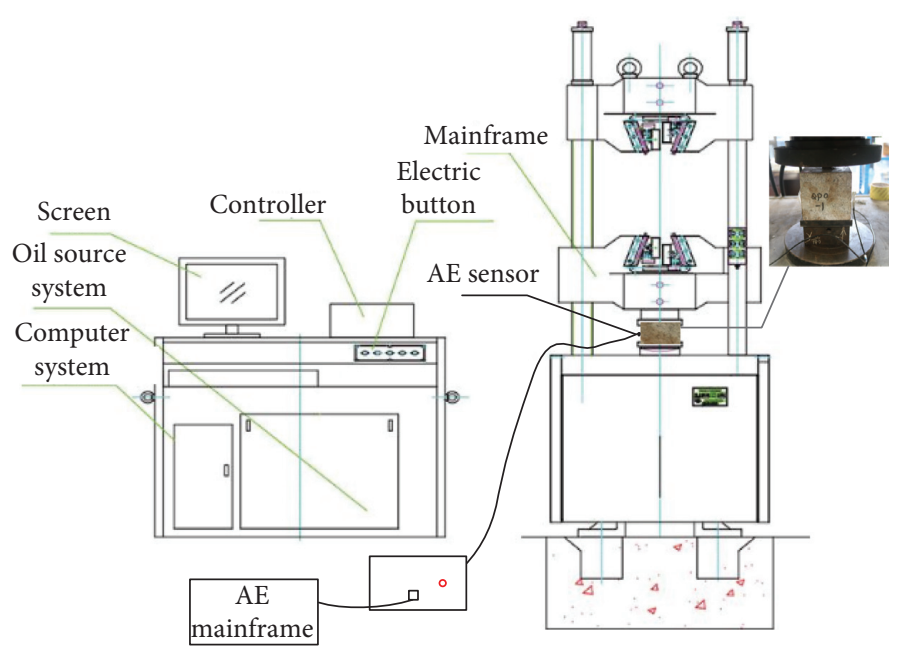

(b)

Figure 5: Schematic diagram of bolt pull-out test system. (a) Loading test system. (b) Drawing test system diagram.

\subsection{Analysis of Test Results}

3.3.1. Load-Slip Curve. Figure 6 shows the load-slip curve in the drawing test. It could be seen from the figure that the resin anchoring agent had good toughness; when the slip was $6.46 \mathrm{~mm}$, the load reached a peak value of $34.82 \mathrm{kN}$. Inorganic materials showed obvious brittleness: (1) The maximum load was $45.27 \mathrm{kN}$ when the slip was $4.8 \mathrm{~mm}$ and the blank superfine cement was used for anchorage. (2) When the cement PO.525 was used for anchorage, the maximum load was $58.93 \mathrm{kN}$ when the slip was $5.05 \mathrm{~mm}$. (3) When the new full-length anchoring material was anchored, the maximum load reaches $66.75 \mathrm{kN}$ when the slip was $3.26 \mathrm{~mm}$. From the experimental data, in terms of anchoring force performance, the new full-length anchoring material has improved the anchoring force by $91.7 \%$ compared with resin anchoring agent. Compared with blank ultrafine cement, the anchoring force was increased by $47.44 \%$. Compared with ordinary silicate anchoring force was increased by $13.27 \%$. The slip displacement of the new full-length anchoring material was $49.5 \%$ less than that of the resin anchoring agent. Compared with blank ultrafine cement, the slippage was reduced by $32.08 \%$. Compared with ordinary silicate slippage was reduced by $35.44 \%$; in terms of the damage form, the resin anchoring agent was used to damage the contact surface between the anchoring agent and the surrounding rock. It showed that the resin anchoring agent has a good bond with the bolt but a little bad bond with the surrounding rock. When the inorganic anchoring agent was used for full-length anchoring, the damage was between the 
bolt and the anchoring agent. It showed that the inorganic full-length anchoring material has good bonding property with surrounding rock.

3.3.2. Shear Modulus. Shear modulus was an important index to describe the mechanics of materials and refers to the ratio of shear stress to strain within the proportional limit of elastic deformation. The shear modulus was large; that is, the hardness was large, the rigidity was strong, and the resistance to deformation was strong. The shear modulus of different materials during elastic stage is shown in Figure 7. It could be seen from Figure 7 that the shear modulus of resin anchorage agent was the lowest, about $0.17 \mathrm{GPa}$. The shear modulus of blank ultrafine cement group was $0.82 \mathrm{GPa}$, the shear modulus of PO.525 cement was $1.01 \mathrm{GPa}$, and the shear modulus of the new full-length anchorage material was $1.92 \mathrm{GPa}$. Compared with the blank group, the shear strength of the new full-length anchorage material was increased by $134.2 \%$. The results indicate that the new full-length anchoring material can improve the hardness of the material and resist deformation better after the interaction of various components.

3.4. Acoustic Emission Characteristics of Full-Length Anchoring Materials. When the stress level of the material exceeds its previous maximum stress level, a large number of acoustic emission events will occur [22]. Most material deformations and fractures occur by sound emission; by analyzing the acoustic emission count and energy in the process of material destruction, the change rule of acoustic emission in the process of destruction was obtained. Figure 8 shows the relationship between $\mathrm{AE}$ counts and accumulated AE energy and stress changes of each sample during anchorage force test.

Figure 8(a) shows that a small number of acoustic emission events occur in resin anchorage samples at the initial loading stage. The AE counts increase obviously at $47.5 \mathrm{~s}$, and the accumulated AE energy increases at the first stage in the $50 \mathrm{~s}$. It was followed by a short period of calm and a large increase at $60.98 \mathrm{~s}$ was shown, indicating that the sample was destroyed greatly. As could be seen from Figure 8(b), the blank ultrafine cement sample was always accompanied by acoustic emission counts during the loading process. At $40.12 \mathrm{~s}$, the accumulated AE energy had showed a significant increase, indicating that the sample suffered sustained damage during loading. From Figure 8(c), it can be seen that the accumulated energy of AE increased significantly after $77.4 \mathrm{~s}$. Then there was a period of stability, and the acoustic emission technology was increased sharply at $100.2 \mathrm{~s}$. The cumulative energy of $\mathrm{AE}$ was increased significantly, indicating that the damage degree of the sample became more and more serious. As can be seen from Figure $8(d)$, it was relatively stable in the early stage. At $105.85 \mathrm{~s}$, the AE counts increased, and the accumulated AE energy increased significantly. From the data synthesis, it could be concluded that the new anchorage material experiences a longer calm period than other materials. Strong

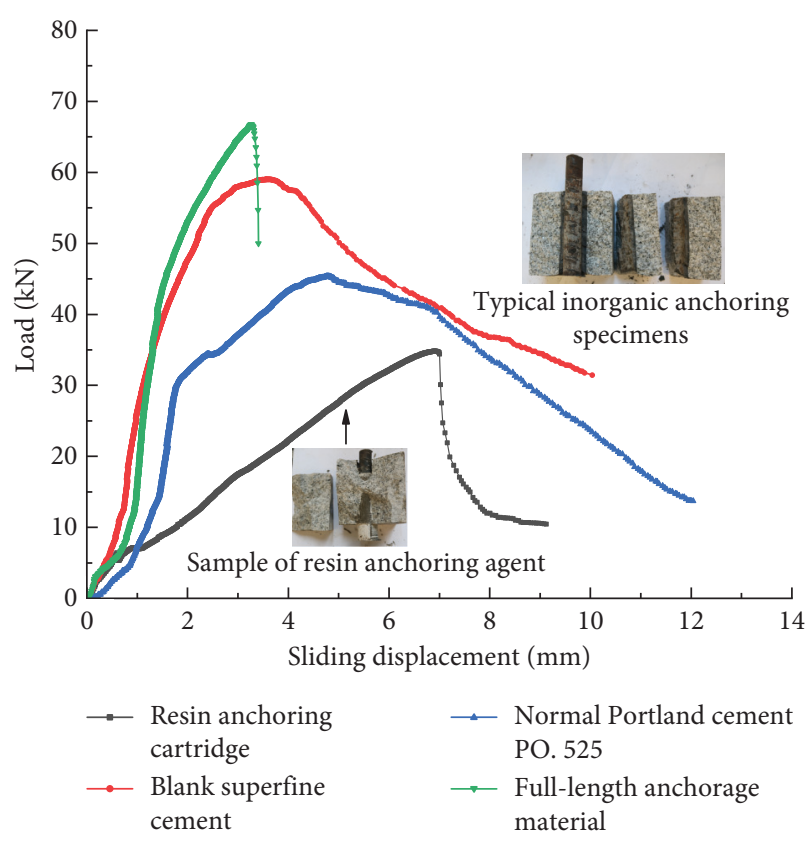

Figure 6: Load-slip curves of different materials.

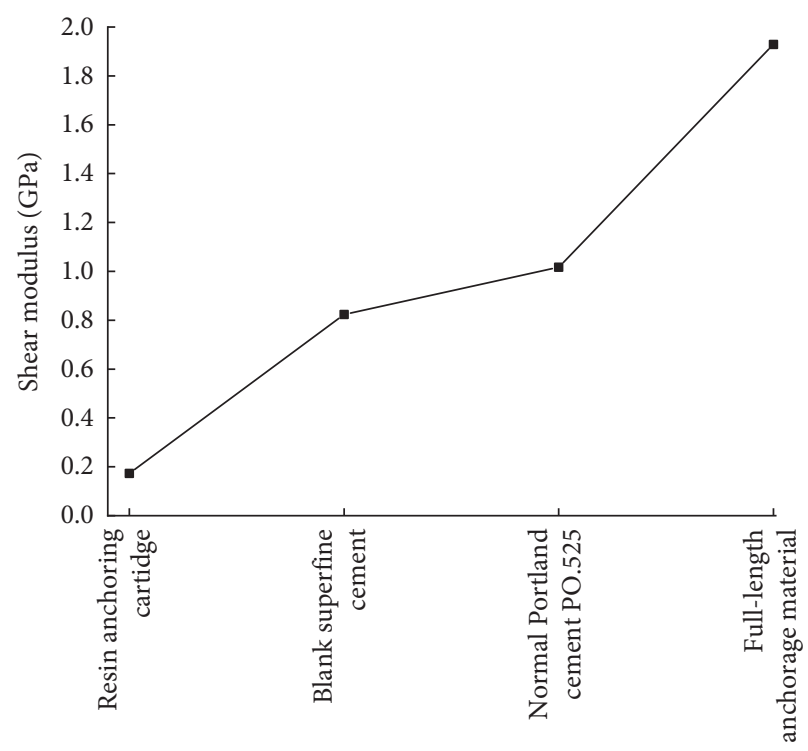

Figure 7: Shear modulus of different materials.

stability, large bearing capacity, and good anchorage performance were shown in the early stage.

\section{Micromorphology of Failure Section}

In this paper, SEM scanning was used to obtain the microstructure characteristics of the shear failure section between the resin anchoring agent and the full-length anchoring material, which could better understand the microstructure of the material. The damaged sections are shown in Figure 9 and Figure 10. As can be seen from Figure 9, the molecular particles of resin anchoring agent 


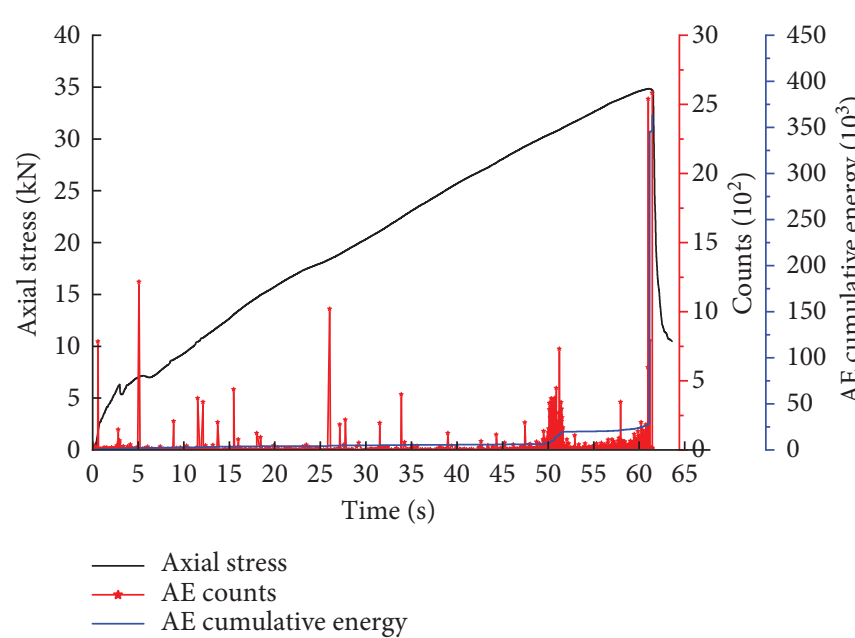

(a)

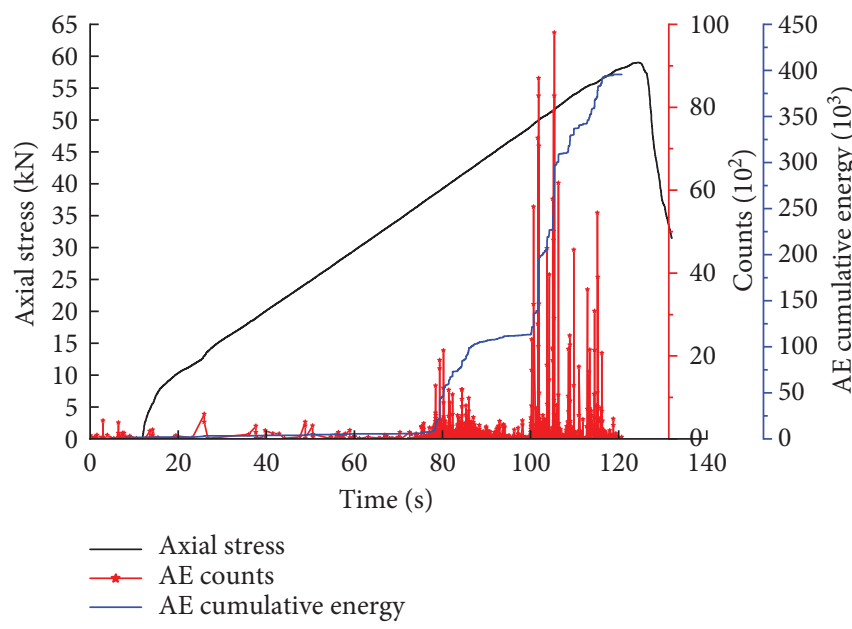

(c)

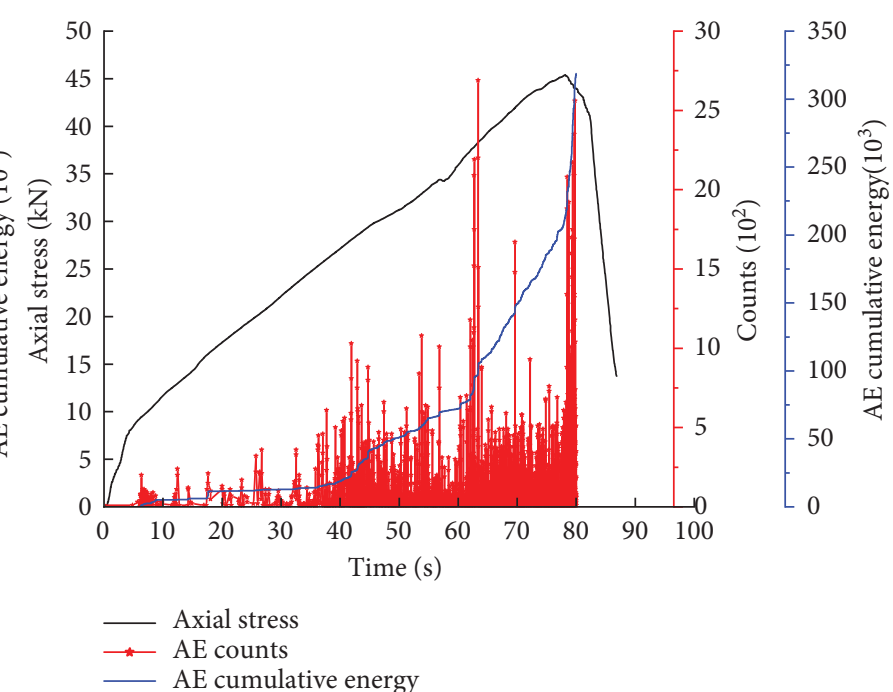

(b)

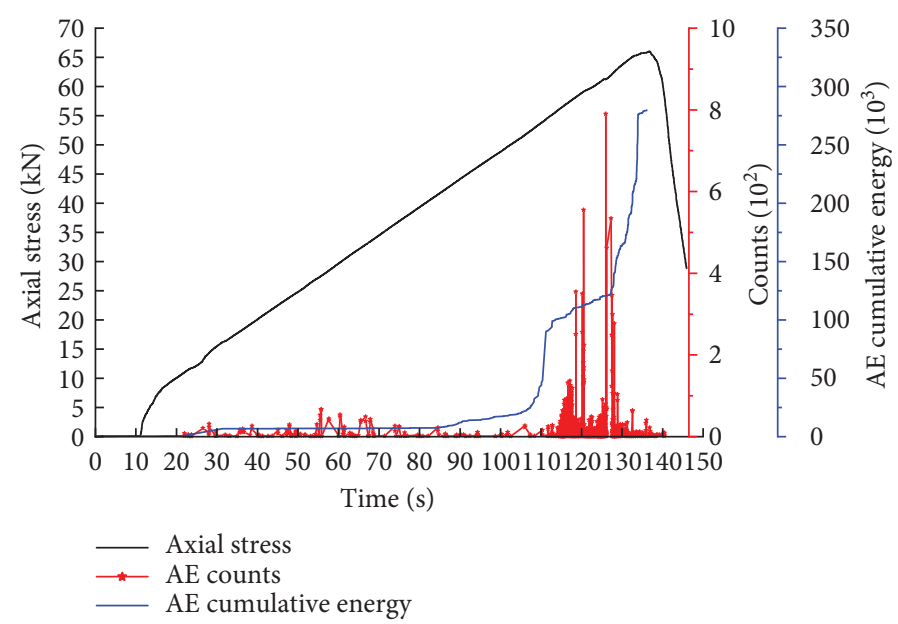

(d)

FIGURE 8: Relationship between time of anchorage specimen and AE counts-cumulative energy and axial stress.
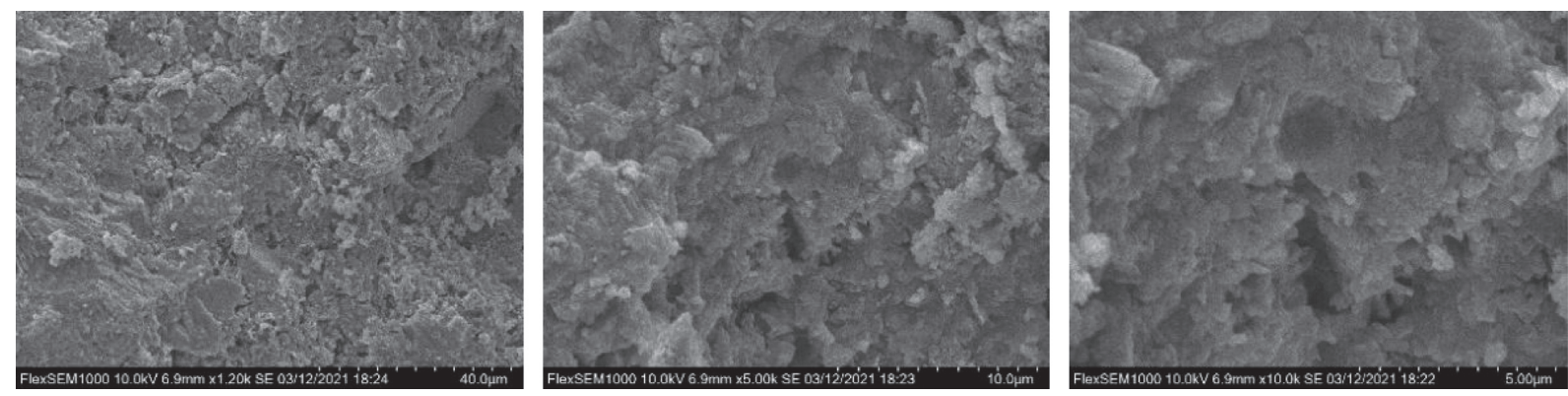

FIGURE 9: SEM of resin anchoring cartridge.

were obvious, and there were pores and some fluffy interface. Very significant pores could be seen and the strongly supported gel was loosened. As could be seen from Figure 10, each component of the full-length anchorage material had undergone hydration reaction, very dense between the molecules, basically no fluffiness, no cracks and bubbles, good section cementation, continuous hydration effect, and high fracture toughness. The results showed that the new full-length anchorage material had reasonable minerals, and the stone body was compact after hydration reaction of each 

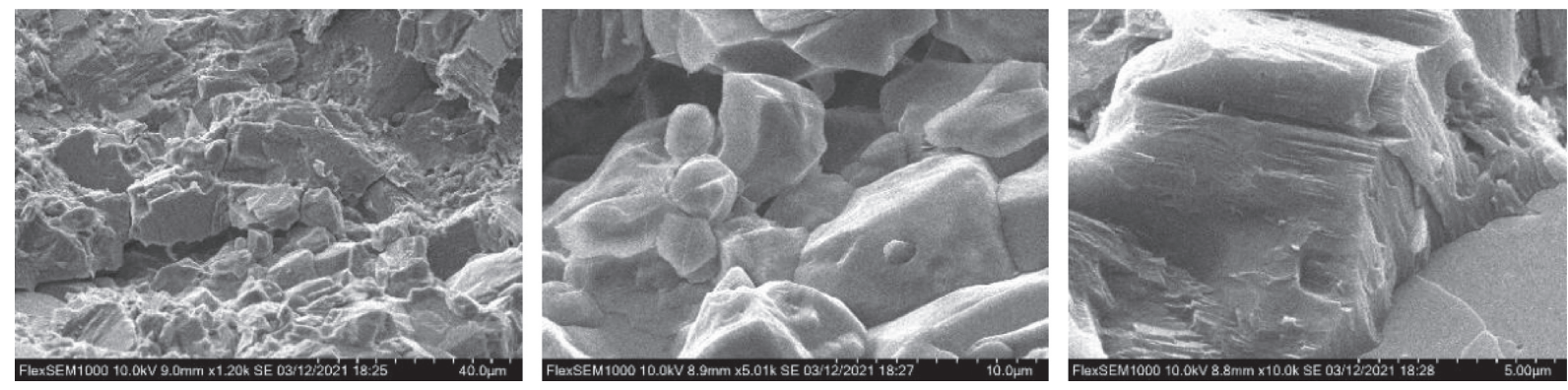

Figure 10: SEM of full-length anchorage material.

component. The interfacial bonding strength was high, and the coupling degree with rock was good. The mechanical properties and long-term stability of the full-length anchoring materials were ensured.

\section{Conclusions}

(1) Through material ratio test, the optimal combination of full-length anchoring materials is as follows: component A about $15 \%$, component B about 3\%, component $\mathrm{C}$ about $0.2 \%$, component $\mathrm{D}$ about $1 \%$, and component $\mathrm{E}$ about $1 \%$, optimal performance and high strength were under this dosage.

(2) The material properties were obtained through the drawing test: full-length anchorage material $>$ ordinary Portland cement $>$ blank superfine cement $>$ resin anchoring cartridge. The anchoring force of superfine cement could be increased by $47.44 \%$ by proportioning full-length anchoring agent. Compared with ordinary silicate materials, the anchoring force was increased by $13.27 \%$.

(3) According to the experimental data, compared with resin anchoring agent, as well as blank superfine cement, the shear modulus of ordinary Portland cement was greatly improved. The results indicate that the new full-length anchoring material could improve the hardness of the material and resist deformation better after the interaction of various components.

(4) According to the AE monitoring during the anchorage force test, the full-length anchoring material experienced a long calm period and strong toughness, strong bore capacity, and good anchoring performance were shown.

(5) SEM test results showed that, after hydration reaction, each component of the new full-length anchorage material was cemented together to form an internal compact structure, which improves the internal density and the cohesion of the material.

\section{Data Availability}

The data used to support the findings of this study are available from the corresponding author upon request.

\section{Conflicts of Interest}

The authors declare that there are no conflicts of interest regarding the publication of this paper.

\section{Acknowledgments}

This research was supported by the National Natural Science Foundation of China (Grants nos. 51974009, 51874002, and 52004005), Key Research and Development Projects in Anhui Province(Grant no. 201904A07020010), Leading Talents Project of Anhui Province's “Special Support Plan"), Anhui Provincial Natural Science Foundation (no. 2008085QE222), independent research fund of the State Key Laboratory of Mining Response and Disaster Prevention and Control in Deep Coal Mines (Anhui University of Science and Technology, no. SKLMRDPC19ZZ012), Anhui University of Science and Technology Introduction of Talents Research Fund Project, Scholastic Key Project (no. QN2019113), Patent Transformation and Cultivation Project (no. ZL201907), Talent Fund of AUST (13200013), and National Natural Science Youth Fund (52004006).

\section{References}

[1] G. Liu, J. Zhao, and H. W. Song, "Numerical simulation study on the influence of joint distribution on rock mass failure," Journal of China University of Mining and Technology, vol. 36, no. 1, pp. 17-22, 2007.

[2] X. Y. Wang, J. B. Bai, and M. Wang, "Mechanism and control technology of inhomogeneous failure of deep inclinated rock roadway under the influence of weak surface," Journal of Mining and Safety Engineering, vol. 32, no. 4, pp. 544-551, 2015.

[3] X. J. Hao, L. Yuan, Y. L. Li et al., "Lateral deformation characteristics of coal with bump tendency based on uniaxial compression experiment," Journal of China University of Mining \& Technology, vol. 47, no. 1, pp. 129-136, 2018.

[4] T. Zhang, L. Yuan, Y. X. Zhao, and X. J. Hao, "Distribution law of working face pressure under the fracture zone distribution characteristic of deep mining," Journal of China Coal Society, vol. 40, no. 10, pp. 2260-2268, 2015.

[5] C. J. Hou, "Key technologies for surrounding rock control in deep roadway," Journal of China University of Mining \& Technology, vol. 46, no. 5, pp. 970-978, 2017.

[6] H. P. Kang, J. Lin, and Y. Z. Wu, "High pretensioned stress and intensive cable bolting technology set in full section and 
application in entry affected by dynamic pressure," Journal of China Coal Society, vol. 34, no. 9, pp. 1153-1159, 2009.

[7] G. H. Wang, X. Y. Wang, J. X. Yang, and X. X. Zhu, "Mechanism analysis of pre-stressed bonded rock bolt controlling the deformation in joint surrounding rocks," Journal of China University of Mining \& Technology, vol. 50, no. 1, pp. 60-68, 2021.

[8] R. S. Yang, Y. L. Li, M. S. Wang et al., "Experimental study of shear mechanical properties of prestressed cable bolts," Journal of China University of Mining \& Technology, vol. 47, no. 6, pp. 1166-1174, 2018.

[9] H. Liu, Research on anchoring characters of non-water reacted polymer grouting materials, Ph.D. thesis, Zhengzhou University, Henan, China, 2019.

[10] Q. Wang and W. Z. Li, "Physical and mechanical performance test and application of modified cement base grouting material," Coal Science and Technology, vol. 44, no. 12, pp. 57-63, 2016.

[11] H. P. Kang, P. F. Jiang, B. X. Huang et al., "Roadway strata control technology by means of bolting-modification-destressing in synergy in $1000 \mathrm{~m}$ deep coal mines," Journal of China Coal Society, vol. 45, no. 3, pp. 845-864, 2020.

[12] A. M. Chen, J. Shen, and X. Xin, "Model experiment study on the different reinforcement effects of un-bonded anchor cable and full-length bonded anchor cable in rock engineering," Chinese Journal of Rock Mechanics and Engineering, vol. 24, no. 15, pp. 2689-2696, 2005.

[13] X. W. Feng, Failure mechanism and durability exploration for fully bonded bolting system, Ph.D. thesis, China University of Mining and Technology, Beijing, China, 2017.

[14] Y. Guo, Y.-q. Wang, Z.-m. Wang, and C.-j. Shen, "Study on the preparation and characterization of high-dispersibility nanosilica," Science \& Engineering of Composite Materials, vol. 23, no. 4, pp. 401-406, 2016.

[15] H. M. Jennings, "A model for the microstructure of calcium silicate hydrate in cement paste," Cement and Concrete Research, vol. 30, no. 1, pp. 101-106, 2000.

[16] P. D. Tennis and H. M. Jennings, "A model for two types of calcium silicate hydrate in the microstructure of Portland cement pastes," Cement and Concrete Research, vol. 30, no. 6, pp. 855-863, 2000.

[17] H. Wang, Y. H. Wang, R. F. Zhang, L. L. Gong, X. D. Cheng, and H. P. Zhang, "Study on porous mullite ceramic material based on orthogonal experimental method," Bulletin of the Chinese Ceramic Society, vol. 32, no. 7, pp. 1389-1393, 2013.

[18] Y. Q. Liu, Y. Sun, D. Infield et al., "A hybrid forecasting method for wind power ramp based on orthogonal test and support vector machine (OT-SVM)," IEEE Transactions on Sustainable Energy, vol. 8, no. 2, pp. 451-457, 2017.

[19] T. Esaki, Y. J. Jiang, and Y. Cai, "A rock bolt and rock mass interaction model," International Journal of Rock Mechanics and Mining Sciences, vol. 41, no. 7, pp. 1055-1067, 2004.

[20] D. Deb and K. C. Das, "Enriched finite element procedures for analyzing decoupled bolts installed in rock mass," International Journal for Numerical and Analytical Methods in Geomechanics, vol. 35, no. 15, pp. 1636-1655, 2011.

[21] F. F. Ren, Z. J. Yang, and J. F. Chen, "An analytical analysis of the full-range behaviour of grouted rockbolts based on a trilinear bond-slip model," Construction \& Building Materials, vol. 24, no. 3, pp. 361-370, 2010.

[22] P. Zeng, "Correlation on frequency characteristics of acoustic emission with stress state of bump-prone rocks," Chinese Journal of Rock Mechanics and Engineering, vol. 36, no. 6, pp. 265-271, 2017. 